\title{
Strategi Pengembangan Wisata Tebat Rasau Di Desa Lintang Kabupaten Belitung Timur
}

\author{
Peranciscus Aryanto*1, Reiza D. Dienaputra ${ }^{2}$, Cecep Ucu Rakhman ${ }^{3}$ \\ Magister Pariwisata Berkelanjutan, Sekolah Pascasarjana Universitas Padjadjaran, Indonesia ${ }^{1,2}$ \\ Sekolah Tinggi Pariwisata Bandung, Indonesia ${ }^{3}$ \\ Email: peranciscusaryanto@gmail.com
}

\begin{abstract}
Tourism is one of the important sectors whose value and movement is to drive the people's economy and influence other sectors. However, in developing tourism it can have an impact on natural damage, so it needs to be defeated by the uniqueness and condition of the existing area. To develop the tourism that is owned, it needs to be done gradually and continuously so that this sector can move the entire community so that community participation can be realized in real terms. Therefore, this study aims to measure community wisdom in developing the tourism potential of Tebat Rasau in Lintang Village, East Belitung Regency. The research used a qualitative descriptive method. Data collection through interviews and field. The results showed that the community was able to encourage tourism development as evidenced by the development and infrastructure, the object of marketing tourism objects through social media and participation in training activities. The research results can be used as a driving force for tourism development in Lintang Village, East Belitung Regency.
\end{abstract}

Keywords: Community, Tourism Development Strategy, Tebat Rasau.

\begin{abstract}
Abstrak
Pariwisata menjadi salah satu sektor penting yang memiliki nilai dan keuntungan dalam menggerakkan perekonomian masyarakat dan berpengaruh pada sektor lainnya. Namun, dalam pengembangan pariwisata dapat membawa pengaruh bagi kerusakan alam, sehingga perlu disesuaikan dengan keunikan dan kondisi wilayah yang ada. Untuk mengembangkan potensi wisata yang dimiliki perlu dilakukan upaya yang bertahap serta berkesinambungan agar sektor ini dapat menggerakkan seluruh masyarakat sehingga partisipasi masyarakat dapat terealisasi secara nyata. Oleh karena itu, penelitian ini bertujuan untuk mengetahui upaya komunitas dalam mengembangkan potensi wisata Tebat Rasau di Desa Lintang Kabupaten Belitung Timur. Penelitian menggunakan metode deskriptif kualitatif. Pengumpulan data melalui wawancara dan observasi lapangan. Hasil penelitian menunjukkan bahwa komunitas mampu mendorong pengembangan pariwisata yang terlihat dengan adanya pembangunan sarana dan prasarana, pemasaran objek wisata melalui media sosial dan berperan serta dalam kegiatan pelatihan. Adapun hasil penelitian dapat digunakan sebagai pendorong pengembangan wisata Desa Lintang Kabupaten Belitung Timur.
\end{abstract}

Kata Kunci: Komunitas, Strategi Pengembangan Wisata, Tebat Rasau.

\section{A. PENDAHULUAN}

Pariwisata merupakan salah satu sektor industri yang berpengaruh terhadap pertumbuhan dan perkembangan ekonomi di Indonesia. Pariwisata adalah kegiatan perjalanan yang dilakukan oleh seseorang atau sekelompok orang pada waktu tertentu dengan mengunjungi tempat yang menarik, bukan untuk mendapatkan uang maupun berbisnis melainkan berekreasi sesuai dengan keinginan yang akan dicapai. Hal ini tentu saja akan mendorong seluruh stakeholder secara bersama - sama dalam menyusun strategi pengembangan pariwisata yang akan dilakukan dan difokuskan pada pembangunan pariwisata yang berkelanjutan dengan mengidentifikasi potensi yang dimiliki dan karakter masyarakat. Pengembangan pariwisata akan memberikan dampak peningkatan devisa negara, terciptanya lapangan

* Corresponding author

Received: July 01, 2021; Revised: July 25, 2021; Accepted: July 29, 2021 
pekerjaan, peningkatan kesejahteraan masyarakat, peningkatan pendapatan daerah dan masyarakat lebih co creation, (Nafi'ah et al., 2020 ; Rinuastuti et al., 2019 ; Sutiarso, 2018). Namun, di sisi lain pengembangan pariwisata juga dapat memiliki dampak negatif terhadap lingkungan, ekonomi dan sosial seperti kerusakan lingkungan yang diakibatkan oleh pengembangan infrastuktur pariwisata, peningkatan harga barang lokal dan perubahan pola hidup masyarakat, (Yusuf \& Hadi, 2020 ; Haque et al., 2020).

Pariwisata yang berkelanjutan merupakan konsep pembangunan pariwisata yang bertanggung jawab terhadap aspek lingkungan, sosial - budaya dan ekonomi untuk tetap terjaga dengan melibatkan peran wisatawan, stakeholder dan masyarakat lokal. Aspek lingkungan berkaitan dengan pengelolaan kelestarian alam dan lingkungan dalam membangun sarana dan prasarana serta infrastruktur yang melibatkan masyarakat, pemerintah serta dunia usaha. Aspek sosial budaya berkaitan dengan penyesuaian terhadap kultur dan budaya masyarakat dan interaksi antara wisatawan dengan masyarakat untuk mengenal warisan budaya masyarakat. Aspek ekonomi berkaitan dengan peluang kerja dan peluang bisnis dalam mendorong pertumbuhan industri pariwisata serta ekonomi kreatif seperti kerajinan tangan dan cindera mata. Pariwisata berkelanjutan perlu dikembangkan dalam mengembangkan daerah yang memiliki potensi wisata dimana pembangunan harus merata dan menyebar ke setiap daerah. Untuk itu dibutuhkan sifat keterbukaan dalam proses sinkronisasi pembangunan yang berfokus pada pendayagunaan sumber daya manusia dan sumber daya alam, dimulai dari perencanaan, pemetaan, pengembangan sehingga dapat menggali potensi wisata yang dimiliki. Pemetaan ini akan memberikan manfaat agar dapat mengidentifikasi dan menganalisis potensi sehingga dapat memberikan gambaran karakteristik dan kondisi objek wisata (Budiani et al., 2018)

Pembangunan pariwisata secara komprehensif dan berkelanjutan harus didukung melalui koordinasi antar lintas bidang dan sektor, penataan kawasan strategis, pemberdayaan dan peningkatan peran serta dari usaha mikro, kecil dan menengah yang berada di sekitar destinasi pariwisata. Keberadaan Badan Promosi Pariwisata serta kelembagaan kepariwisataan seperti asosiasi kepariwisataan sangat penting di dalam pembangunan kepariwisataan karena asosiasi ini sangat berperan aktif sebagai mitra dari Pemerintah Daerah. Selain itu juga harus ada penetapan standarisasi jenis usaha, kompetensi pekerja pariwisata dan pemberdayaan sumber daya manusia pariwisata melalui pelatihan agar dapat meningkatkan kualitas dan pengetahuan mereka. Pembangunan pariwisata berkelanjutan ini dapat memberikan dampak yang besar terhadap pemasukan dan pendapatan daerah maupun negara sehingga Pemerintah Daerah dapat merasakan perubahan. Oleh karena itu pembangunan pariwisata akan mengalami peningkatan apabila potensi pariwisata yang dimiliki daapat dikembangkan secara berkelanjutan. Konsep pembangunan berkelanjutan tidak akan terlepas dari konsep pembangunan sebagai upaya pemanfaatan pembangunan yang berlansung secara berkesinambungan dengan wawasan kelestarian budaya serta berbasiskan kepentingan masyarakat (Yanuarita, 2018).

Desa Lintang terletak di dalam kecamatan Simpang Renggiang Kabupaten Belitung Timur, Provinsi Kepulauan Bangka Belitung. Desa ini merupakan salah satu dari 39 (tiga puluh sembilan) desa yang ada di Kabupaten Belitung Timur dengan Indeks Desa Membangun dengan kategori berkembang. Desa ini memiliki luas wilayah sekitar 2.309 hektar dan jumlah penduduk 2.830 orang (1008 Kepala Keluarga). Desa ini dapat ditempuh dengan waktu 45 (empat puluh lima) menit dari Bandara HAS Hanandjoeddin Tanjung Pandan. Potensi yang dimiliki adalah bidang perkebunan, pertambangan dan pariwisata. Mata pencaharian penduduk adalah petani, buruh tani, peternak, nelayan, karyawan perusahaan swasta dan Pegawai Negeri Sipil. Bidang pertambangan yang dihasilkan adalah pasir, pasir kwarsa dan timah. Bidang pariwisata terdapat danau (wisata air, hutan wisata dan situs purbakala) yang dikenal dengan nama Tebat Rasau. Bidang perkebunan yang dihasilkan adalah lada, karet dan kelapa sawit. Tingkat pendidikan masyarakat di Desa Lintang lebih didominasi oleh lulusan Sekolah Menengah Pertama, sedangkan tingkat pendidikan sarjana jumlahnya sangat minim. Objek wisata Tebat Rasau 
menjadi salah satu potensi pariwisata yang ada di Desa Lintang. Objek wisata ini memiliki potensi alam sungai purba yang masih alami serta keanekaragaman flora dan fauna. Pemerintah Daerah ikut serta dalam pengembangan objek wisata ini dengan menjadikan objek wisata ini sebagai salah satu Destinasi Prioritas Pemerintah Kabupaten Belitung Timur yang ditetapkan melalui Keputusan Bupati Belitung Timur Nomor 188.45 - 249 Tahun 2020 tentang Destinasi Wisata Prioritas dan Super Prioritas di Kabupaten Belitung Timur. Namun, aksesibilas seperti jalan, sarana transportasi, infrastruktur perjalanan kaki yang belum optimal di lokasi Tebat Rasau serta informasi yang masih terbatas menyebabkan minat wisatawan untuk berkunjung ke lokasi ini masih sangat minim, terlebih faktor keselamatan dan kenyamanan sangat penting bagi pengunjung dalam menikmati sebuah obyek wisata.

Terbatasnya kemampuan sumber daya manusia yang terampil dan profesional dalam mengelola dan mengembangkan potensi pariwisata dan budaya menjadi permasalahan dalam mengembangkan Objek Wisata Tebat Rasau. Maka dari itu tulisan ini bertujuan untuk mengetahui upaya komunitas dalam mengembangkan potensi wisata Tebat Rasau di Desa Lintang Kabupaten Belitung Timur.

\section{B. METODE PENELITIAN}

Penelitian ini menggunakan metode deskriptif kualitatif. Penentuan subjek menggunakan purposive sampling dengan dasar pemilihan pada keikutsertaan atau keterlibatan langsung subjek dalam pengembangan wisata Tebat Rasau supaya sesuai dengan tujuan penelitian. Subjek dalam penelitian 10 orang di Desa Lintang yang mencakup masyarakat, ketua komunitas, pendamping desa, Pemerintah Desa serta Dinas Kebudayaan dan Pariwisata Kabupaten Belitung Timur. Data dikumpulkan melalui observasi lapangan dan wawancara. Data yang diperoleh dianalisis secara deskriptif menggunakan model analisis menurut (Miles et al., 2014) yaitu pengumpulan data, reduksi, penyajian data dan penarikan kesimpulan.

\section{HASIL DAN ANALISIS}

Data penelitian ini diperoleh dari hasil wawancara dengan masyarakat, ketua komunitas, pendamping desa, Pemerintah Desa serta Dinas Kebudayaan dan Pariwisata Kabupaten Belitung Timur melalui observasi dan dokumentasi penelitian. Data primer dalam penelitian ini adalah pemahaman masyarakat Desa Lintang mengenai potensi wisata Tebat Rasau.

\section{Potensi pariwisata di Objek Wisata Tebat Rasau}

Kawasan wisata Tebat Rasau ini terbentuk akibat perubahan bumi dan sungai yang ada di Tebat Rasau ini merupakan pecahan bumi bagian atas. Di sungai ini sendiri banyaksekali jenis - jenis ikan dan menjadi habitat spesies primitive seperti Asian Arowana (Scleropages formosus) yang memiliki nenek moyang ikan purba sehingga sungai ini terindikasi sebagai jejak sungai purba. Namun, saat ini populasi Asian Arowana merupakan spesies yang terancam punah dan termasuk dalam IUCN Red List (Djapani et al., 2021). Menurut cerita sesepuh masyarakat, sungai purba ini dulunya sering di lalui oleh kelompok Lanun atau perompak dan untuk mencegah masuknya para perompak, masyarakat menanam Rasau untuk menghalangi perahu kelompok Lanun yang akan masuk ke perkampungan. Dalam kehidupan sehari - hari, masyarakat lokal bergantung pada sumber daya alam yang ada di sungai dan hutan. Keanekaragaman air tawar dan tanaman yang ada di kawasan ini juga dapat dijadikan sebagai laboratorium alam.

Masyarakat lokal secara turun temurun memiliki kemampuan dalam memanfaatkan dan mengelola sumber daya alam yang ada seperti cara menangkap ikan menggunakan alat tradisional yang terbuat dari bambu dan dikenal dengan sebutan siro serta menggunakan tumbuhan sebagai bumbu dalam masakan. Tanaman Rasau menjadi ciri khas di kawasan ini karena tumbuh subur di rawa dan sungai. Berbagai jenis tanaman herbal, juga menjadi potensi yang sangat besar untuk dijadikan sebagai .produk 
obat herbal dan minuman herbal. Keanekaragaman hayati dan warisan geologi mempengaruhi budaya masyarakat setempat yang dapat terlihat dari cara menangkap dan mengelola sumber daya alam yang ada di kawasan Tebat Rasau.

\section{Pengembangan Objek Wisata Tebat Rasau}

Pengembangan kawasan Geowisata Tebat Rasau dikelola oleh Komunitas Lanun yang terbentuk pada tahun 2018 dimana komunitas ini beranggotakan masyarakat setempat. Penentuan nama Lanun di dasarkan pada sejarah sungai purba, namun dalam perspektif artian saat ini lebih kepada semangat untuk menjaga kelestarian alam dan sungai. Komunitas Lanun melakukan koordinasi dengan berbagai pihak, sehingga secara bertahap pembangunan sarana dan prasarana pendukung mulai terlihat di kawasan ini. Konsep yang ditawarkan di kawasan ini adalah wisata yang berbasis alam dimana wisatawan yang berkunjung akan mendapatkan pengetahuan geologi, biodiversity dan kearifan lokal. Komunitas ini sangat menjaga kelestarian lingkungan dengan menjaga keanekaragaman hayati yang ada sehingga terlihat asri dan menarik. Kemudian dari berbagai jenis tanaman diolah menjadi produk obat herbal dan minuman yang disajikan kepada wisatawan yang berkunjung. Untuk atraksi yang dilakukan masyarakat akan disuguhkan penampilan sanggar Betiong Begubang yang beranggotakan para orang tua yang menampilkan tarian sambil berpantun. Sajian makan bedulang, kopi tanggar (dengan campuran susu), minuman rempah teh sepang dan teh pelawan menjadi suguhan yang sangat menarik. Selain aktivitas wisata, kegiatan yang bertemakan pendidikan alam melalui Sekolah Alam juga dilakukan di tempat ini. Hal ini bertujuan agar anak - anak dapat mengenal budaya serta alam sejak dini agar mereka dapat menjadi bagian dalam menjaga ekosistem alam sehingga dapat tetap terjaga.

Menurut informasi dari ketua komunitas, dalam beberapa bulan ini terjadi penurunan partisipasi masyarakat dalam komunitas yang ada terhadap pengembangan potensi wisata Tebat Rasau. Partisipasi masyarakat di dalam pembangunan pariwisata sangatlah penting dengan meletakkan dasar keyakinan bahwa masyarakat lebih mengetahui apa yang sangat dibutuhkan. Keterlibatan masyarakat dalam setiap tahapan pembangunan yang dimulai dari perencanaan, pengambilan keputusan, serta pengawasan program pengembangan desa wisata.sehingga dapat mendorong mereka berpartisipasi aktif dalam pelaksanaan dan pengawasan (Sidiq \& Resnawaty, 2017). Partisipasi dapat didefinisikan sebagai bentuk keikutsertaan seseorang dalam suatu kelompok sosial dalam mengambil bagian di dalam kehidupan sosial masyarakat, di luar dari profesi dan pekerjaan sendiri. Dengan demikian partisipasi dapat diukur melalui tiga pendekatan, yaitu:

a) Dimensi pemikiran, yaitu partisipasi pikiran dalam pengembang desa wisata seperti ide pengembangan, pembuatan paket program, hingga penggunaan media.

b) Dimensi tenaga, yaitu kontibusi dalam bentuk tenaga fisik seperti partisipasi dalam pengembangan area kunjungan, pemandu wisata, pembuatan saran prasarana dan pembuatan peralatan penunjang kegiatan.

c) Dimensi materi, yaitu kontribusi dalam pengumpulan dana untuk pembangunan kawasan wisata (Murdiyanto, 2011)

Di dalam pengembangan pariwisata, Pemerintah Kabupaten Belitung Timur telah mengeluarkan Keputusan Bupati Belitung Timur Nomor 188.45 - 150 Tahun 2019 tentang Geosite Prioritas Pengembangan Geopark Pulau Belitung di Kabupaten Belitung Timur dimana Objek Wisata Tebat Rasau ditetapkan sebagai salah satu Geosite prioritas di Kabupaten Belitung Timur. Penetapan ini didasarkan pada fungsi objek wisata sebagai geotourism, lingkungan, kebudayaan, ilmu pengetahuan dan pendidikan. Di dalam pengelolaan wisata Tebat Rasau, telah 
dilakukan oleh komunitas ini memiliki visi menjadikan Tebat Rasau sebagai Objek Wisata yang mengedukasi, dengan berbasis budaya dan peningkatan kewirausahaan lokal dengan misi :

a) Bersinergi dengan pemerintah (daerah, propinsi dan pusat), masyarakat dan dunia usaha dalam menjaga kelestarian alam,

b) Memajukan pengetahuan tradisional sebagai literasi budaya lokal,

c) Memaksimalkan peran serta pemangku kepentingan dalam meningkatkan kewirausahaan masyarakat,

d) Menciptakan Tebat Rasau sebagai ruang publik bagi masyarakat untuk berkreativitas,dan

e) Menjadikan Tebat Rasau sebagai sentra industri berbasis kebudayaan dan alam dengan pelibatan multi pihak secara aktif, edukatif, transparan dan profesional.

f) Objek Wisata Tebat Rasau ini memiliki filosofi sebagai berikut:

1) Manusia memiliki dan mengembangkan wujud ide, gagasan, nilai, norma, peraturan, dsb

2) Kebudayaan sebagai suatu kompleks aktivitas serta tindakan berpola dari manusia dalam masyarakat

3) Kebudayaan menghadirkan pemaknaan juga pola prilaku adaptasi terhadap alam dan lingkungan sosial

4) Kesepakatan bersama dalam berbudaya dalam membangun komunitas guna menjaga alam yang merupakan titipan Tuhan Yang Maha Esa

Geosite Tebat Rasau yang terletak di Desa Lintang sendiri saat ini memiliki potensi yang luar biasa seperti atraksi seni dan budaya, susur sungai, kuliner dan potensi flora dan fauna.

\section{Atraksi (Attraction)}

Geosite Tebat Rasau memiliki atraksi wisata yang unik dan bisa menjadi daya tarik bagi wisatawan yang berkunjung seperti :

a) Susur sungai, melihat species ikan Arwana, ikan Buntal dan capung sambil menggunakan perahu

b) Permainan gasing

c) Membuat kerajinan dari kayu

d) Jelajah hutan rasau

e) Penampilan sanggar seni Betiong Begubang (menari sambil berbalas pantun)

f) Memasak makanan tradisional Belitong dengan penyedap makanan alami dan menyajikan dalam bentuk makan bedulang.

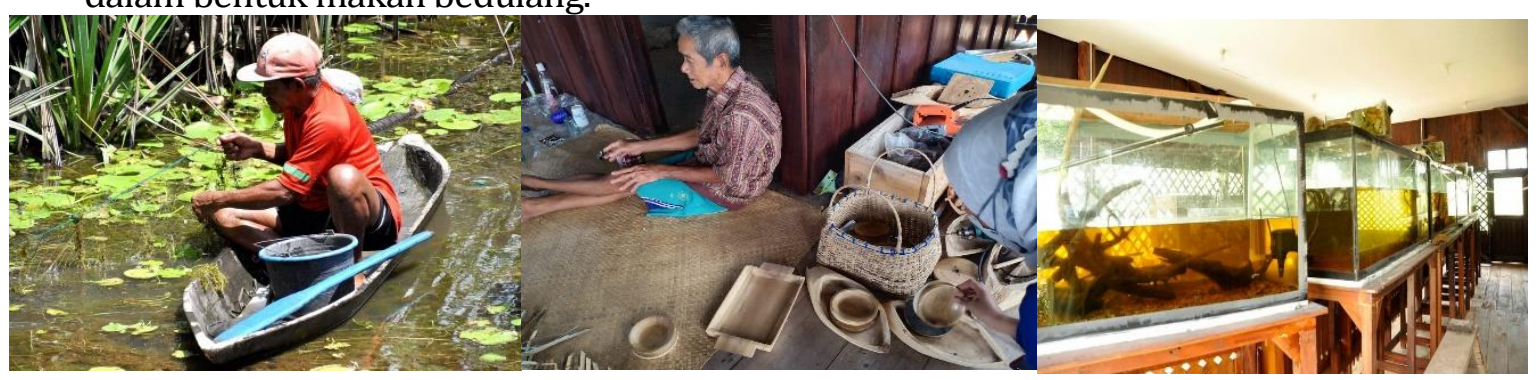

Gambar 1. Susur Sungai
Gambar 2. Kerajinan dari kayu
Gambar 3. Ikan Arwana 

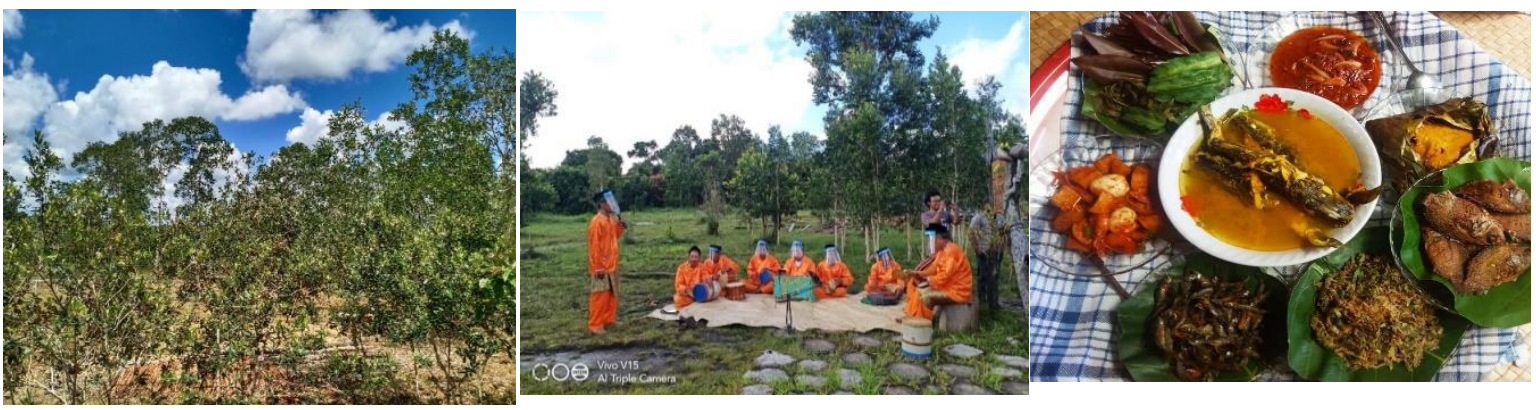

\section{Gambar 4. Jelajah Hutan Rasau}

\author{
Gambar 5. Penampilan \\ Sanggar Seni Betiong \\ Begubang
}

\author{
Gambar 6. Makan \\ Bedulang
}

\section{Aksesibilitas (Accesibility)}

Untuk mengunjungi Geosite Tebat Rasau, pengunjung dapat melalui jalan raya utama yang biasa dikenal dengan Jalan Tengah dengan jarak tempuh kurang lebih $70 \mathrm{~km}$ dan waktu 45 menit. Sarana transportasi yang tersedia dapat menggunakan kendaraan pribadi yang dapat disewakan dan untuk menemukan tempat ini dapat menggunakan google map dan mudah dijumpai karena telah tersedia rambu - rambu penunjuk jalan. Namun masih ada kekurangan yang dapat terlihat dimana ada beberapa ruas jalan yang kecil dan untuk menuju ke dalam Geosite Tebat Rasau masih tanah merah.

\section{Fasilitas (Amenity)}

Di objek wisata Tebat Rasau terdapat fasilitas yang cukup memadai seperti sekretariat Tebat Rasau yang menjadi titik point untuk memulai kegiatan wisata. Kemudian ada rumah Gasing dan didepannya terdapat lapangan permainan gasing. Bangunan lainnya adalah rumah untuk aquarium yang berisikan jenis - jenis ikan, kemudian trekking yang menjadi unggulan favorit untuk menikmati pemandangan tanaman rasau. Bungalouw dapat disewakan kepada wisatawan yang menginap dan ingin menikmati alam. Kemudian galeri souvenir untuk menampilkan hasil kerajinan yang dapat diijadikan souvenir menarik serta fasilitas umum seperti musholla dan toilet.

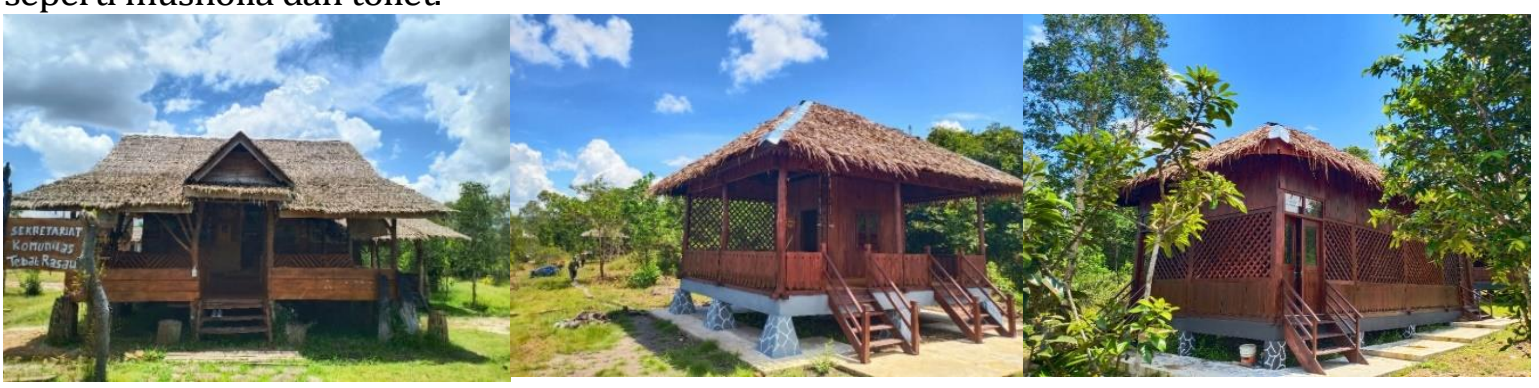

Gambar 7. Sekretariat

Gambar 8. Rumah Gasing

\section{Gambar 9. Rumah \\ Aquarium}




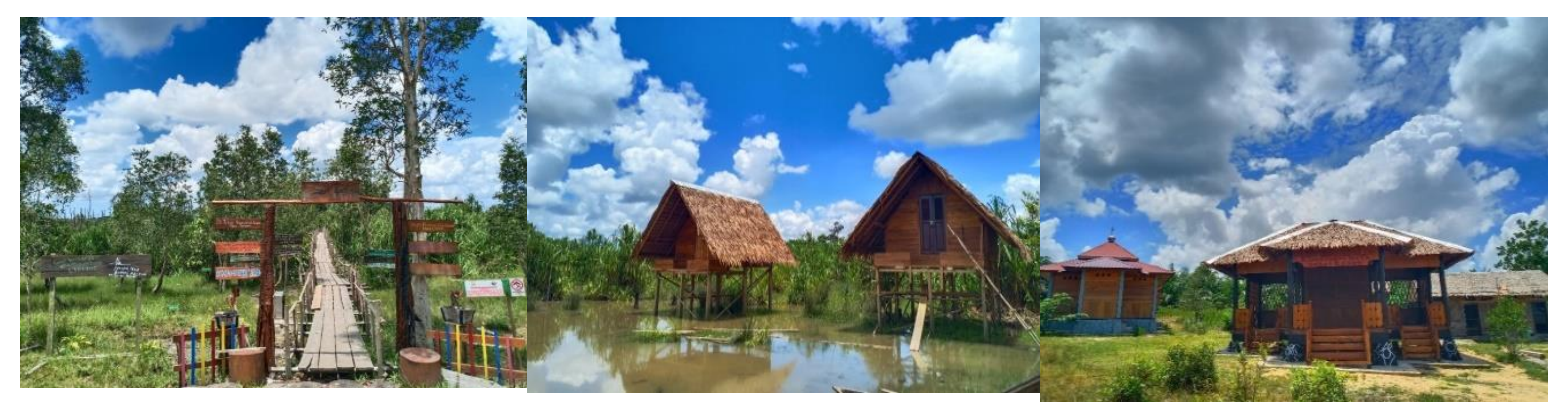

Gambar 10. Trekking
Gambar 11. Bungalouw

\section{Gambar 12. Galeri \\ Souvenir}

\section{Pelayanan Tambahan (Ancilliary)}

Objek Wisata Tebat Rasau memiliki komunitas yang dinamakan komunitas Lanun, dimana pada awalnya jumlah anggota yang terlibat dalam komunitas ini. Namun dengan adanya pelatihan dari Dinas Kebudayaan dan Pariwisata Kabupaten Belitung Timur serta pembangunan sarana prasarana yang mendukung pengembangan wisata Tebat Rasau, maka masyarakat antusias untuk berperan serta di dalam komunitas.

Dari penjelasan dan gambar di atas dapat diketahui bahwa wisata yang ada di Tebat Rasau sangat berpotensi untuk dikembangkan. Sumber daya manusia dan sumber daya alam yang dimiliki menjadi nilai yang penting dalam memajukan pariwisata di Kabupaten Belitung Timur. Untuk ke depannya pengembangan potensi wisata ini akan tertuju pada pelestarian alam dan ekosistem sungai, pendidikan dan penelitian, pelestarian budaya lokal, kepariwisataan dan kewirausahaan.

\section{KESIMPULAN}

Pengembangan wisata Tebat Rasau di Desa Lintang, peran serta komunitas sangat penting di dalam mengelola potensi yang dimiliki. Strategi yang dilaksanakan komunitas bersama Dinas Kebudayaan dan Pariwisata Kabupaten Belitung dalam bentuk pelatihan serta pembangunan sarana dan prasarana dapat menjadi pendorong untuk kemajuan pariwisata di Kabupaten Belitung Timur dan meningkatkan kesejahteraan masyarakat.

\section{Daftar Referensi}

Budiani, S. R., Wahdaningrum, W., Yosky, D., Kensari, E., Pratama, H. S., Mulandari, H., Iskandar, H. T. N., Alphabettika, M., Maharani, N., Febriani, R. F., \& Kusmiati, Y. (2018). Analisis Potensi dan Strategi Pengembangan Pariwisata Berkelanjutan Berbasis Komunitas di Desa Sembungan, Wonosobo, Jawa Tengah. Majalah Geografi Indonesia, 32(2), 170-176. https://doi.org/10.22146/mgi.32330

Djapani, Y., Sulaksana, N., \& Muljana, B. (2021). Peranan Komunitas Lokal Dalam Perencanaan Pengembangan Geosite Di Kawasan Geopark Belitong. Jurnal Academia Praja, 4(1), 6488. https://doi.org/10.36859/jap.v4i1.268

Haque, A., Astuti, W., \& Mukaromah, H. (2020). Jayengan Kampung Permata ditinjau dari kesesuaian terhadap konsep pariwisata berkelanjutan. Region: Jurnal Pembangunan Wilayah Dan Perencanaan Partisipatif, 15(2), 152-171. https://doi.org/10.20961/region.v15i2.24416

Miles, M. B., Huberman, A. M., \& Saldana, J. (2014). Qualitative Data Analysis; A Methods 
Sourcebook. Arizona State University.

Murdiyanto, E. (2011). Partisipasi Masyarakat Dalam Pengembangan Desa Wisata Karanggeneng, Purwobinangun, Pakem, Sleman. Sepa, 7(2), 91-101. https://doi.org/https://doi.org/10.20961/sepa.v7i2.48893

Nafi'ah, Z., Ayu, D. T. L., \& Kurniawan, R. A. P. (2020). Kapitalisasi Pengelolaan Pariwisata Berbasis Komunitas (Studi Kasus Wisata Sumber Maron, Desa Karangsuko, Kecamatan Pagelaran, Kabupaten Malang). Journal of Governance Innovation, 2(1), 68-76. https://doi.org/10.36636/jogiv.v2i1.370

Rinuastuti, B. H., Saufi, A., \& Asmony, T. (2019). Pengaruh Positif Pariwisata Terhadap Kepuasan Hidup Dan Nilai Co Creation Pada Komunitas Di Lingkar Kek Mandalika. Jmm Unram - Master of Management Journal, 8(3), 234-243. https://doi.org/10.29303/jmm.v8i3.444

Sidiq, A. J., \& Resnawaty, R. (2017). Pengembangan Desa Wisata Berbasis Partisipasi Masyarakat Lokal Di Desa Wisata Linggarjati Kuningan, Jawa Barat. Prosiding Penelitian Dan Pengabdian Kepada Masyarakat, 4(1), 38-44. https://doi.org/10.24198/jppm.v4i1.14208

Sutiarso, M. A. (2018). Pengembangan Pariwisata Yang Berkelanjutan Melalui Ekowisata. 1-11. https://doi.org/10.31219/osf.io/q43ny

Yanuarita, H. A. (2018). Pembangunan Pariwisata Berkelanjutan: Studi tentang Pengembangan Wisata Gua Selomangleng di Kota Kediri. Publik (Jurnal Ilmu Administrasi), 7(2), 136-147. https://doi.org/10.31314/pjia.7.2.136-146.2018

Yusuf, I., \& Hadi, T. S. (2020). Studi Literatur: Dampak Pengembangan Pariwisata Terhadap Perubahan Lahan. Pondasi, 25(2), 157-183. https://doi.org/10.30659/pondasi.v25i2.13041 